\title{
Dysplasia Spondyloepiphysaria Congenita and Related Generalized Skeletal Dysplasias Among Children with Severe Visual Handicaps
}

\author{
G. R. FRASER, ^ A. I. FRIEDMANN, P. MAROTEAUX, \\ A. M. GLEN-BOTT, and U. MITTWOCH
}

From The Department of Research in Ophthalmology, Royal College of Surgeons, London; Clinique de Génétique Médicale, Hôpital des Enfants Malades, Paris; The Department of Anatomy, St. Thomas Hospital Medical School, London; and Galton Laboratory, University College, London

In 1963-5, a study was made of the causes of severe visual handicap among 776 children in special schools in England and Wales (Fraser and Friedmann, 1967). During this study, it became apparent that a number of these blind children suffered from generalized skeletal dysplasias of poorly-defined types, often associated with subnormal height. The blindness was due usually, but not invariably, to high myopia and retinal detachments. The skeletal dysplasia affected primarily the vertebrae and epiphyses of the long bones with variable metaphysial involvement. Before this survey, the skeletal abnormalities of these children had given rise to a multitude of diagnoses; during the survey, the condition was identified, in some cases at least, as being identical to that described as dysplasia spondyloepiphysaria congenita (Spranger and Wiedemann, 1966a, b; Bach et al., 1967). This is an entity sui generis, and quite distinct from conditions such as MorquioBrailsford disease and dysplasia epiphysialis multiplex (Fairbank, 1947) with which it is sometimes confused, as the following case histories show. The differential diagnosis is discussed further in a subsequent section.

\section{Case Reports}

Case 1 (M 14). $\dagger$ Female born in 1958, birthweight $2465 \mathrm{~g}$. ( $5 \mathrm{lb} .7 \mathrm{oz}$.), was the last born of 4 children of whom the first (a girl) was stillborn, and the remaining 2 (1 boy, 1 girl) are normal as are the parents. The father was 39 years and mother was 30 years at the

Received March 3, 1969.

*Present address-Division of Medical Genetics, Department of Medicine, University of Washington, Seattle, 98105, U.S.A.

†These designations refer to the complete report of this survey (Fraser and Friedmann, 1967). birth of the infant; there was no consanguinity between the parents.

Shortness of the neck and of the long bones was noted at birth and, initially, a diagnosis of achondroplasia was made. This was subsequently modified to one of Morquio-Brailsford disease, but, in fact, she has neither of these conditions and is probably, a case of dysplasia spondyloepiphysaria congenita. At the time of survey, at the age of 5 years, she was dwarfed, with kyphoscoliosis and short limbs and a round, flat face with a flattened nasal bridge (Fig. 1).

Several series of skeletal $x$-rays were available for examination, including some taken in utero. They showed marked shortening of the shafts of the long bones, especially in the shoulder and hip regions and deformity of the femoral and humeral epiphyses (Fig. 2). The epiphyses were involved to a lesser extent than the metaphyses. There was generalized flattening of the vertebral bodies which were of oval shape and of irregular outline (Fig. 3).

At the age of 2 months, it was noted that the ocular pressure was raised bilaterally and that the eyeballs were protruding. Examination under anaesthesia at that time revealed that the corneae were $12 \mathrm{~mm}$. in diameter and contained deep opacities, that both discs were cupped, and that mesodermal remnants were present in the angles of the anterior chambers. A diagnosis of buphthalmos (congenital glaucoma) was made, and cyclodialysis was performed, but without success; subsequently, the child rapidly became blind. At the time of survey, the appearance of the eyes was that of buphthalmos, with large numbers of vitreous opacities. The remainder of the medical history of this child reveals two unexplained episodes of transient glycosuria and ketonuria in infancy associated with listlessness and loss of weight. She made somewhat slow progress in her milestones, including walking and speech. Her hearing is thought to be unimpaired, but she is probably mentally subnormal.

Detailed qualitative studies of urinary mucopolysaccharides failed to reveal any abnormality. The amino acid excretion pattern was also normal. 

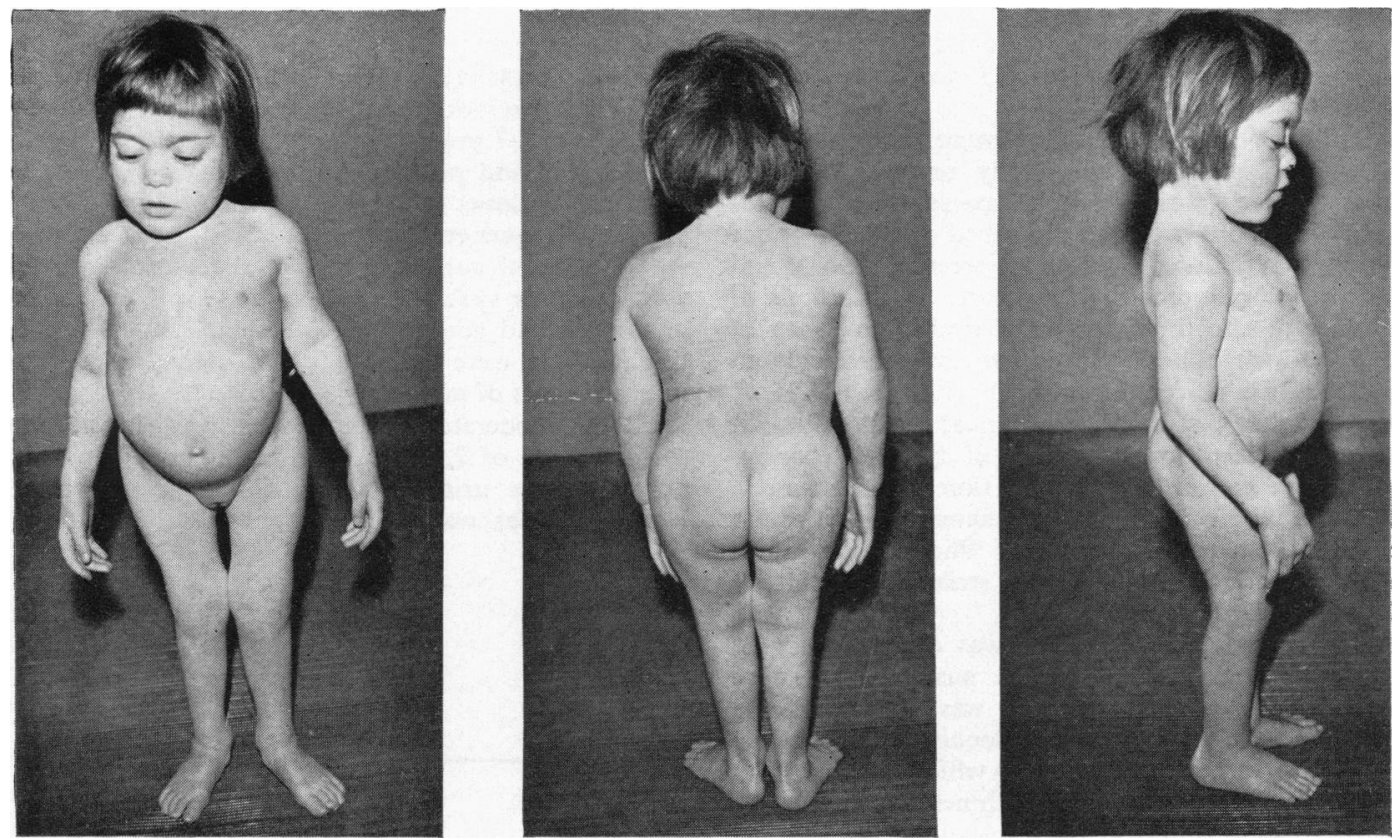

Fig. 1.-Case 1 at the age of 8 years.

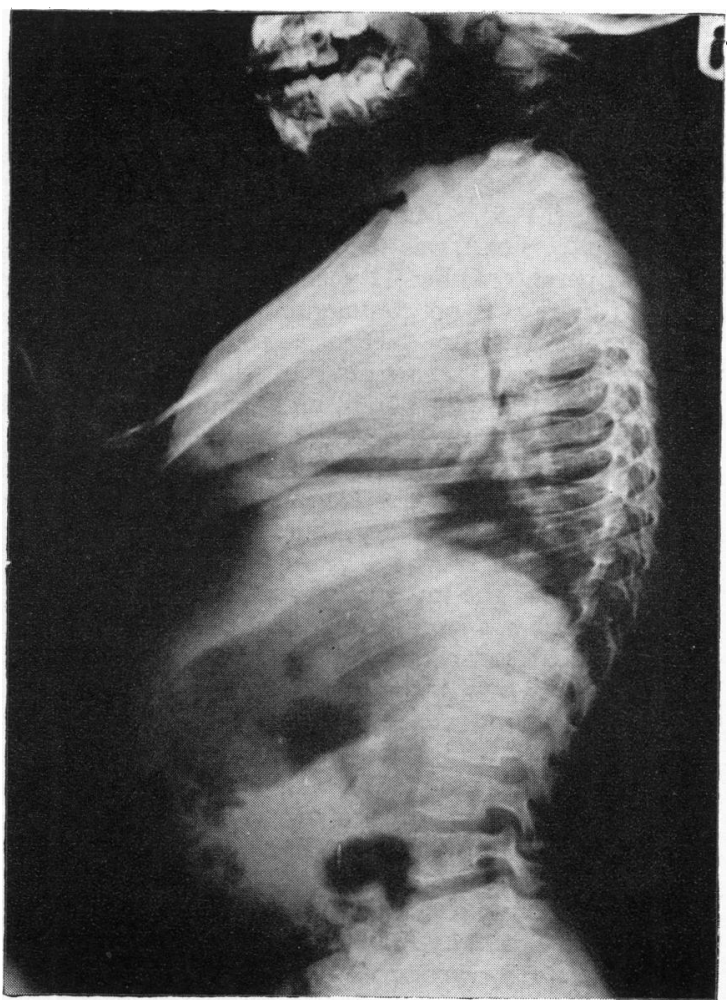

Fig. 3.-X-ray of Case 1 at the age of 5 years, showing

flattening and irregularity of the vertebral bodies.

FIG. 2.-X-ray of Case 1 at the age of 5 years, showing considerable abnormalities of the femoral necks and iliac wings. The femoral heads are absent.

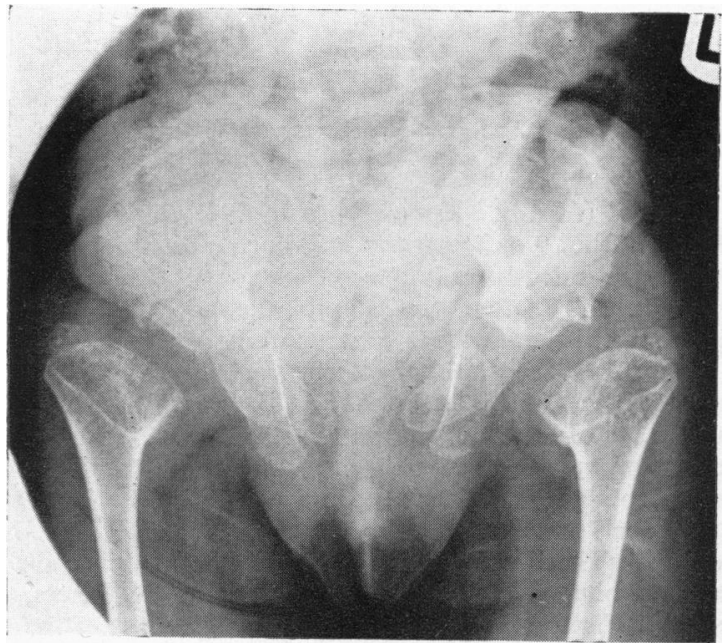


Case 2 (M 8). Male born in 1957, birthweight $3288 \mathrm{~g}$. (7 lb. $4 \mathrm{oz}$.), was the only child of normal nonconsanguineous parents, father 27 years, mother 21 years.

Short limbs and a cleft palate were noted at birth. The cleft palate was subsequently repaired, and his skeletal dysplasia was initially diagnosed as achondroplasia. This child was also described as Case 1 of the paper by Roaf, Longmore, and Forrester (1967), and $x$-rays are reproduced in that report. The lesions of the bones of the limbs are very similar to those of Case 1 , and, though no $x$-ray of the vertebral column is available, the description given by Roaf et al. (1967) leaves no doubt that these appearances are also similar. Thus, he is in all probability a case of dysplasia spondyloepiphysaria congenita. At the time of the survey, aged 5 years, he was dwarfed and showed a flat, round face with a flattened nasal bridge. Photographs reproduced by Roaf et al. (1967) show a striking resemblance to those of Case 1 (Fig. 1).

At the age of 23 months, he was examined by an ophthalmologist on account of a suspicion of poor visual acuity. At that time, he was noted to have vertical nystagmus. Extensive ballooned inferior retinal detachments were seen in both eyes which showed about 10 dioptres of myopia. The detachments subsequently progressed; as a result, at the time of the survey, the child was completely blind with secondary iritis and cataracts in both eyes and, in addition, secondary glaucoma in the left.

$\mathrm{He}$ had moderately severe perceptive deafness affecting primarily the high tones; in addition to his dual sensory deprivation, he was probably mentally subnormal. His karyotype was normal (Roaf et al., 1967), as was his urinary amino acid excretion pattern.

Case 3 (M 9). Male born in 1946, birthweight $2891 \mathrm{~g}$. (6 lb. $6 \mathrm{oz}$ ), was the third-born of 6 children; sibs and parents, father 41 years, mother 31 years, are normal; there was no consanguinity between parents.

At the age of 2 years, skeletal $x$-rays showed irregularity, widening and shortening of the diaphyses and epiphyses of the long bones, and some retardation of the formation of the epiphyses in the heads of the femurs and humeri. A diagnosis of achondroplasia and rickets was made. Normal progress occurred with milestones in infancy, but walking was always difficult. At the age of 4 years, he was admitted to the hospital for the investigation of dwarfism. At the time, his head was large, and he had a flat nasal bridge. The proximal segments of the limbs were especially short. The $x$-rays taken at that time are no longer available, but his skeletal condition was considered then to be of the type of dysplasia epiphysialis multiplex (Fairbank, 1947). It is probable, however, that he is a case of dysplasia spondyloepiphysaria congenita. Thus at the time of the survey, aged 17 years, the patient was dwarfed and showed a flat, round face with a flattened nasal bridge. He was described as Case 2 by Roaf et al. (1967) and the photographs and $x$-ray reproduced there suggest considerable similarity to the skeletal condition of Cases 1 and 2 of the present report.

Gross myopia (12 dioptres in the right and 16 dioptres in the left eye) was first noted at the age of 4 years. At the age of 7 years, a retinal detachment occurred in the left eye and progressed rapidly causing secondary iritis and cataract with blindness. At the age of 10 year, this sequence of events recurred in the right eye. At the time of survey, the right eye showed old iritis with posterior synechiae, and vascularization was noted of the iris and anterior lens capsule. In the left eye, the findings were essentially the same, with superimposed areas of marked iris atrophy.

He has moderately severe perceptive deafness noted since the age of 7 years. His intelligence is probably normal. The urinary amino acid excretion pattern was normal, as was his karyotype (Roaf et al., 1967).

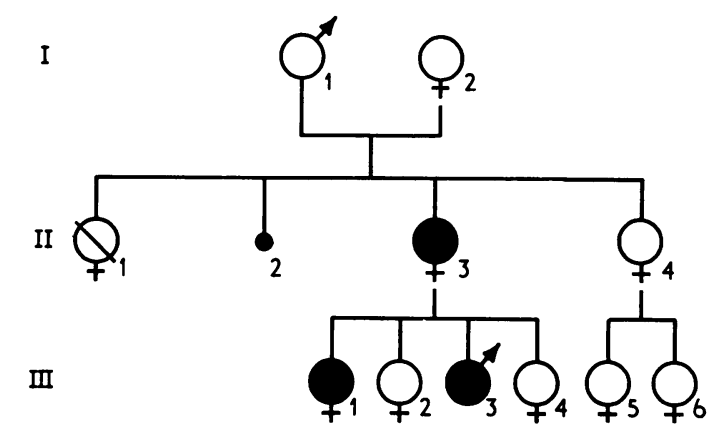

Fig. 4.-The proposita (Case 4) is III.1. II.1 died in infancy, and $I I .2$ represents an abortion.

Case 4 (M 13). Female born in 1947, birthweight $3883 \mathrm{~g}$. ( $8 \mathrm{lb} .9 \mathrm{oz}$.), was the first-born of 4 children of whom the third-born is affected as is also the mother (Fig. 4). The father was 23 years, the mother 21 years at the birth; there was no consanguinity of parents.

Shortness of the limbs affecting especially the proximal segments was noted at birth. At the time of survey, at the age of 15 years, she was small $(152 \mathrm{~cm}$.) and had short limbs; in these respects, she resembled her mother and brother. Full skeletal $x$-rays of all 3 affected individuals were taken and showed remarkable similarities. There were widespread epiphysial abnormalities involving primarily the spine (Fig. 5), knees, elbows (Fig. 6), and wrists without involvement of the metaphyses. In addition, there was marked shortening of the long bones, and the bones of the hand were coarsely modelled. All 3 affected persons had very similar facial abnormalities, the face being round and flat with a very much flattened nasal bridge and somewhat protruding eyes.

All 3 also had severe visual handicaps, though there was considerable variation between them in the nature of the eye defects. In the case of the proposita, reduced visual acuity was suspected before her first birthday, and by the age of 3 years, she was noted to have 18 dioptres of 


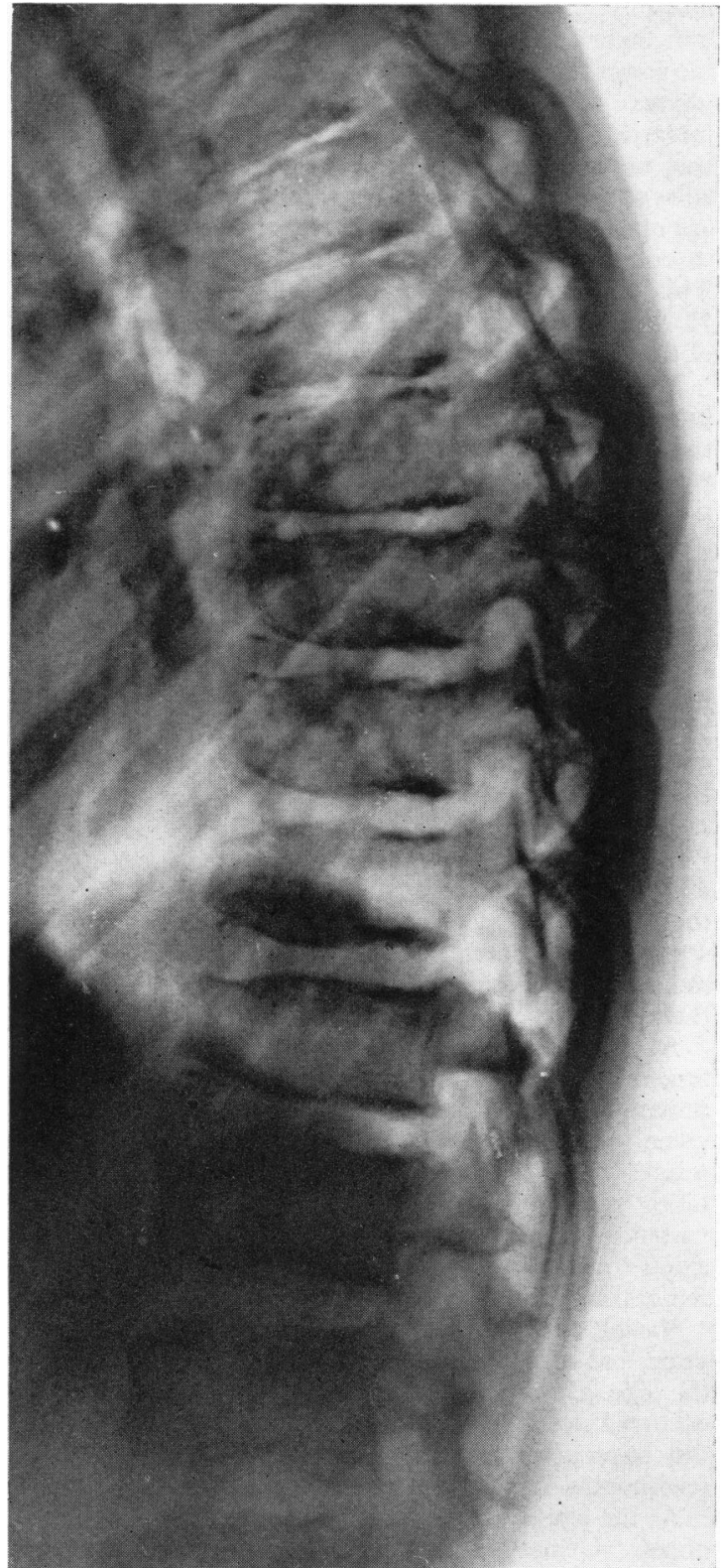

FIG. 5.-X-ray of the brother of Case 4 at the age of 12 years, showing irregularity of the vertebral bodies, with a slight reduction of their height.

myopia bilaterally and retinal detachments. A persistent hyaloid artery and vitreous opacities were seen at that time. The retinal detachments progressed rapidly and at the time of survey, she was completely blind, with secondary cataracts and bound-down pupils.

The evolution of the eye lesion was more benign in

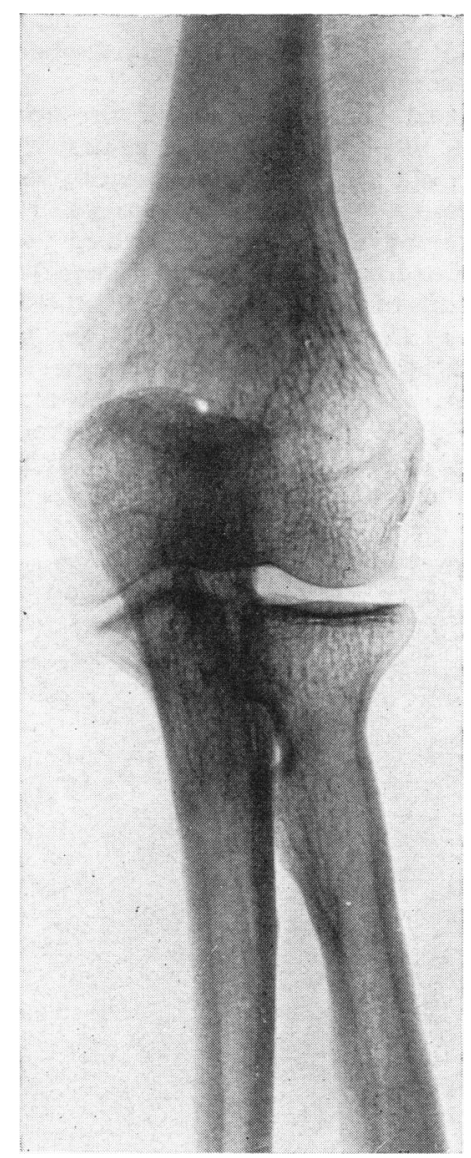

FIG. 6.-X-ray of the mother of Case 4 showing a slight deformity of the head of the radius.

the brother. Again, visual disability was suspected in earliest infancy, and by the age of 2 years, he had myopia of 14 dioptres in the right and 16 dioptres in the left eye. He also had nystagmus and some vitreous opacities. However, he never had retinal detachments, and at the time of survey, when aged 12 years, he had reasonably good visual acuity.

The mother was aged 37 years at the time of survey. Poor sight had been noted since the age of 2 years and, at the age of 3 years, a cataract was needled in the left eye which was noted to be myopic. Subsequently, a cataract in the right eye was needled at the age of 7 years. The operation on the left eye was sufficiently successful for her to go through life as a normallysighted person. At the time of survey, lens remnants were noted in both eyes, and myopic degeneration in both retinae, the right eye being more affected than the left.

All 3 affected individuals had moderately severe perceptive hearing loss, ranging from 30 to 60 decibels and being more pronounced in the high tones than the 
low. Intelligence was unimpaired; indeed, taking into account the visual and auditory disabilities, it was probably above average.

Amino acid chromatography of the urines of the 3 affected individuals showed a normal excretion pattern, as did qualitative and quantitative studies of urinary mucopolysaccharides. Special staining of lymphocytes by the methods described by Mittwoch (1963) revealed no mucopolysaccharide inclusions.

The parents of the mother, aged 69 and 68 years, were examined at the time of survey. They had normal vision and hearing and were of normal height and proportions. The grandmother of the proposita had fibrous dysplasia of the skull; this was regarded as a coincidental finding unrelated to the disabilities of her daughter and grandchildren.

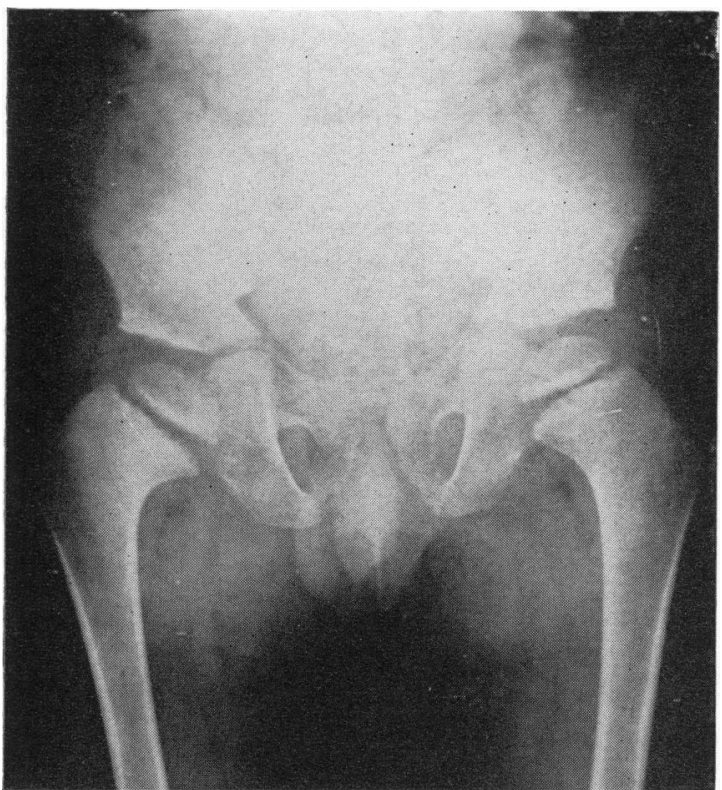

FIG. 7.-X-ray of Case 5 at the age of 4 years showing the involvement of the hips winch is much less severe than in Case 1 (see Fig. 2).

Case 5 (M 10). Male born in 1951, birthweight 2267 g. (5 lb.), was the first-born of 9 children, the last 5 being born of a second marriage of the mother. All the full- and half-sibs are normal as are the parents, whose ages at birth were: father 21 years, mother 20 years; there was no consanguinity between parents.

This boy was also, like Cases 2 and 3, ascertained independently and described as Case 4 by Roaf et al. (1967). His skeletal dystrophy had excited comment since early infancy, and several series of $x$-rays were taken between the ages of 1 and 5 years. The condition was variously diagnosed as osteochondritis, achondroplasia, and osteochondrodystrophy. These $x$-rays were available for examination at the time of survey and showed metaphysial and epiphysial abnormalities. The vertebral bodies were irregular, and marked enlargement of the lower femoral epiphyses with splaying of the metaphyses was seen. In the pelvic region, bilateral infantile coxa vara with slipped capital femoral epiphyses was noted (Fig. 7). The pelvis was narrowed, with enlargement and irregularity of the acetabula. At the age of 4 years, osteotomies of the femurs were performed to correct knee deformities of the genu valgum type. This boy was somewhat short for his age $(129 \mathrm{~cm}$. at 12 years), but did not show any facial abnormalities of the type seen in Cases 1 to 4 .

His eyesight was probably defective from early infancy, but no details are available before he reached the age of 6 years when a marked deterioration of vision was noted. At this time, he already had long-standing ritis bilaterally, with a secondary complicated cataract in the right eye and widespread retinal detachment in the left eye. At the time of survey at the age of 12 years, he had iritis with calcified lenses and superficial peripheral corneal opacities.

He showed a mild perceptive hearing loss, and his intelligence was probably very slightly below normal.

The urinary amino acid excretion pattern was normal, and chromosomal investigation (Roaf et al. 1967) showed a normal male karyotype.

Case 6 (M 11). Male, born in 1950, birthweight 4309 g. (9 lb. 8 oz.), was the second-born of 2 children; the first (a girl) died at the age of 8 days of neonatal sepsis. The parents are normal, father 38 years, mother 34 years; and there is no consanguinity between them.

At the age of 6 years, this boy had short and stubby fingers, and a short neck and a round, flat face with protruding eyes. Extensive investigations were undertaken with a diagnosis of pseudohypoparathyroidism in mind; this possibility was excluded. The $x$-rays taken at that time are no longer available, but showed flattening of the glenoid aspects of the scapulae and slight irregularities of the articular aspects of the distal femoral and capitellar epiphyses and of the left astragalus.

Visual difficulties were first noted at the age of 2 years and at 3 years high myopia was diagnosed. At the age of 6 years, detachment of the right retina occurred leading rapidly to secondary cataract and this sequence of events was repeated in the left eye a few months later.

At the age of 12 years, mild perceptive deafness was noted. Urinary amino acid chromatography at the time of survey revealed a normal pattern of excretion.

Case 7 (M 17). Male, born in 1946, birthweight 3741 g. ( 8 lb. 4 oz.), was the first-born of 2 children, the second (a boy) being normal. The father was 33 years, and the mother 32 years at the birth of the child; no consanguinity between parents. The mother had high myopia since childhood, as did a maternal aunt. At birth, this boy had a flat nasal bridge, prominent eyes, and very large fontanelles. At the age of 2 years, valgus ankles and knock-knees were noted. 
At the age of 8 years, he was short, had stubby fingers, and had orthopaedic treatment because of difficulty in walking associated with his valgoid feet and knockknees. No $x$-rays or reports of $x$-rays are available for examination.

Visual difficulty was first suspected at the age of 2 years when he had myopic astigmatism and rotatory nystagmus. At the age of 4 years, he had developed posterior polar cataracts of irregular shape. At the time of survey, aged 16 years, he had central posterior lens opacities, megalocornea, suggestive of glaucoma, and hypoplasia of the iris.

Moderately severe deafness had been noted since the age of 2 years. Intelligence was normal. Urinary amino acid chromatography showed a normal excretion pattern.

\section{Discussion}

Nature of the skeletal dysplasias. Cases 1-5 are examples of spondyloepiphysial dysplasias. The radiological appearances in Cases 1 and 2 leave no doubt that the skeletal condition of these two children corresponds to that described by Spranger and Wiedemann (1966a, b) and by Bach et al. (1967) as dysplasia spondyloepiphysaria congenita (DSC). Though only very sparse radiological data are available, the clinical features of Case 3 suggest that he also suffers from this condition.

In these patients (Cases 1, 2, and probably 3), growth disturbances were already apparent at birth or were noted very soon afterwards. There is marked growth retardation mainly due to shortness of the trunk. There is a deformity of the sternum which projects forward and also considerable lumbar lordosis. The limbs are short, but the hands and feet are normal.

Radiologically, the skeletal lesions involve particularly the vertebral column and the hips. The vertebral bodies are of reduced height and of ovoid shape. The femoral heads and necks are extremely abnormal. The centre of ossification of the head is absent, and the neck is hypoplastic with irregular contours. Involvement of other epiphyses, on the other hand, is less marked, and is limited to excessive translucency and some irregularities.

Cases 4 and 5 differ somewhat from the previous three children in that modifications of the vertebral column predominate, especially in Case 4 and her affected relatives. Involvement of the hips, on the other hand, is considerably less severe, especially in Case 4 and her affected relatives. Thus, Cases 4 and 5 cannot be unequivocally identified as examples of DSC, though their condition is likely to be closely related. Certainly stunted growth is a feature of Case 4 and her affected relatives, and, in this family, facial appearances and body pro- portion are similar to those seen in Cases 1-3.

On the basis of clinical criteria, Cases 6 and 7 may also be examples of the group of spondyloepiphysial dysplasias represented by Cases 1 to 5 . In the absence of radiological data, however, no firm diagnoses can be made.

Nature of the ocular defects. In all these children except Case 1, the primary defect leading to visual handicap seems to be high myopia. This has been of unfavourable evolution, and intractable retinal detachments have occurred at a variable age in infancy or childhood, leading to secondary cataracts, iritis, and glaucoma, and to virtual blindness. It should be remembered, however, that the children of the present survey were selected through serious visual handicap, and, therefore, it is possible that less severe ocular involvement may occur among cases of DSC and related spondyloepiphysial dysplasias which are not selected in this manner. Indeed, while high myopia or retinal detachments are mentioned in some probable instances of DSC reported (Braun and Meythaler, 1962; Spranger and Wiedemann, 1966a, b; McKusick, 1966; Bach et al., 1967), in others (Kniest, 1952; Uhlig, 1954; Cigala and Golino, 1964; Lenz, 1964) no abnormalities of the eyes are described.

Other forms of eye involvement were seen in this series. Thus, blindness is due to buphthalmos in Case 1: this is exceptional, since buphthalmos has never been previously reported in association with DSC. However, gonioscopy in the case of Braun and Meythaler (1962) showed mesodermal remnants in the anterior chamber angle similar to those seen in Case 1. Furthermore, von Noorden, Zellweger, and Ponseti (1960) have suggested that the anomalies of mesodermal tissue found in the angles of anterior chambers in children with inherited disorders of mucopolysaccharide metabolism may also exist in other connective tissue diseases. Thus, it seems possible that the myopia of this syndrome is only part of a more extensive ocular malformation complex which may occasionally be manifested by buphthalmos.

Finally, primary cataracts have occurred in possible cases of DSC seen in this series (Case 7, mother of Case 4). Cataracts in infancy have also been reported in association with ill-defined skeletal dysplasias in sporadic cases by Hatt (1952) and Nordio and Mantovani (1956). Such cataracts are, in addition, a feature of Conradi's syndrome; this is an autosomal recessive condition (Fraser and Scriver, 1954) and is not a likely diagnosis among any cases of the present series. 
Hearing loss and other features. Apart from the skeletal and ocular involvement, moderately severe perceptive deafness is a feature of all the cases in this series except, probably, Case 1. Though deafness does not figure among the reported cases of DSC, with the exception of the possible case of Cigala and Golino (1964), the extent of the hearing loss among the cases of the present survey is not great, and it might well be overlooked, especially when the skeletal lesions form the primary interest of the observer.

Mental subnormality was suspected in Cases 1 and 2 , as in the case of DSC reported by Bach et al. (1967). It may be, therefore, that this is a relatively frequent accompaniment of this condition. Cases 3 to 7, however, were of normal or superior intelligence.

Cleft palate occurred in Case 2, as in the patient of Bach et al. (1967), and was mentioned by Spranger and Wiedemann (1966b) in a further case. Possibly, therefore, this might be considered a facultative component of the DSC syndrome.

As is to be expected, the karyotype has been normal in the four cases examined, i.e. Cases 2, 3, and 5 of the present series (Roaf et al., 1967) and the patient of Bach et al. (1967). Biochemical investigations, including urinary amino acid chromatography, have not shown any abnormality. In particular, studies of urinary mucopolysaccharide excretion patterns have given normal results. Spranger and Wiedemann (1966b) found inclusions in a proportion of lymphocytes and monocytes in 5 of their 6 patients. The inclusions were similar to those described by Gasser (1950) in cases of abnormalities of mucopolysaccharide metabolism. Such inclusions, however, were not found in the affected members of the family of Case 4 of the present series.

Genetics. There is good evidence that DSC is inherited in a dominant manner (Spranger and Wiedemann, 1966a, b; and the possible case of Lenz (1964)), as are the associations of ocular and skeletal defects in Cases 4 and, probably, 7 of the present series. It is not entirely clear, however, whether DSC or some other, possibly related, skeletal dystrophy is involved in these 2 cases.

It is probable that the fertility of persons with these syndromes is much reduced, since they often suffer from hearing and visual loss in addition to dwarfism. In such circumstances, a large proportion of cases would be expected to be due to freshly arisen mutations. While such a phenomenon cannot be unequivocally detected, parental age at the birth of such 'sporadic' cases may give useful circumstantial evidence of the presence of new mutations which are often associated with an increase in paternal age (Penrose, 1961).

The mean parental ages at the births of the sporadic cases of this series $(1,2,3,5,6)$ were $33 \cdot 7$ years for fathers and 27.7 years for mothers. Control data from this survey of blind children give values of 31.6 for fathers and 28.5 years for mothers (Fraser and Friedmann, 1967). Thus the difference between parental ages (6.0 years) is considerably greater than the control value of $3 \cdot 1$ years, suggesting an increase in paternal age consistent with the causation of these children's condition by freshly arisen mutations.

Differential diagnosis of dysplasia spondyloepiphysaria congenita. The differential diagnosis of DSC has been extensively discussed by Spranger and Wiedemann (1966a, b) and by Bach et al. (1967). Among other spondyloepiphysial dystrophies which must be distinguished are Morquio's disease (autosomal recessive) and dysplasia spondyloepiphysaria tarda (Maroteaux, Lamy, and Bernard, 1957) which is sex-linked recessive. These diseases, as well as the pseudoachondroplastic (Lamy and Maroteaux, 1960b) type of spondyloepiphysial dysplasia, are not congenital and differ in many respects from the condition under discussion.

Among congenital spondyloepiphysial dysplasias it is relatively easy to differentiate this condition from achondroplasia and from diastrophic (Lamy and Maroteaux, 1960a) and metatropic (Maroteaux, Spranger, and Wiedemann, 1966) dwarfism. Finally, purely epiphysial dysplasias, such as Conradi's syndrome of stippled epiphyses with congenital cataract (autosomal recessive) and dysplasia epiphysialis multiplex (autosomal dominant) of Fairbank (1947), may be excluded because of differences in the age of onset, in the nature of the osseous lesions, and in the distribution of the bones involved.

Some help in the differential diagnosis may be given by the ocular and auditory involvement. Thus, the affected members of the family of Case 4 might have been diagnosed as suffering from dysplasia epiphysialis multiplex if the congenital nature of the affection had not been known and if they had not shown ocular and auditory lesions. However, the ocular lesions are not specific, and the presence of buphthalmos (Case 1) may cause some superficial confusion with the mucopolysaccharidoses, and more especially with the 'forme fruste' of Hurler's syndrome described by Scheie, Hambrick, and Barness (1962), while the presence 
of primary cataracts (Case 7 and the mother of Case 4) may cause similar superficial confusion with Conradi's syndrome.

Association of visual defect with DSC and other skeletal dysplasias. It is well known that involvement of the eye which may lead to gross visual defect may occur in association with a wide variety of skeletal dysplasias. Such associations of Marfan's syndrome, Conradi's syndrome, osteogenesis imperfecta, and mucopolysaccharidoses with visual defects are particularly well discussed by McKusick (1966). The present series contained, in addition to the 7 cases described above, 5 further probable examples of these associations. In 3 cases, Marfan's syndrome was suspected and in 2 others osteogenesis imperfecta. No cases of Conradi's syndrome or of mucopolysaccharidoses were identified. Severe visual handicap seems, therefore, to be more common when present in association with DSC and the possibly related skeletal dystrophies described here than with these well-known conditions.

While Cases 1 to 3 of the present report are, in all probability, examples of DSC, other entities, possibly related to but distinct from DSC, may be included among Cases 4 to 7. Unfortunately, radiological data in these children are sparse, and in some cases, non-existent, so that accurate diagnoses are difficult. Lamy and Maroteaux (1960b) and Silverman (1961) have discussed the problems in exact diagnoses of epiphysial dysplasias that can arise, even when adequate serial $x$-rays are available, because of the marked changes in radiological appearances that take place during development. If any of these children do suffer from a condition that is distinct from DSC, then it is one which is currently undesignated. It may be that the clinical condition of DSC is merely one facet of an entire spectrum of phenotypic variation due to a single genetic entity, but in the absence of the possibility of experimental breeding, such an hypothesis can be neither proved nor disproved. Phenotypic variability of this sort may to some extent be apparent rather than real and due to observer bias; because of such effects superimposed on the already considerable variability naturally present, a disease which represents a single genetical entity may often masquerade under a variety of different diagnostic labels.

A search of the literature has revealed several further families in which dominantly inherited associations of ocular defects with ill-defined skeletal dysplasias and, in some instances, with hearing losses, have occurred (David, 1954;
Rosenbloom and Smith, 1965; Moore and Federman, 1965; Stickler et al., 1965; Stickler and Pugh, 1967; Frandsen, 1966). Some of these families could represent conditions related to DSC but in others distinct entities are undoubtedly involved.

The range of genetically-determined associations of visual and skeletal defects seems very wide, and further ill-defined entities, inherited in an autosomal recessive rather than dominant manner, are represented by Cases $M 16$ and $M 18$ of the complete report of this survey of 776 blind children by Fraser and Friedmann (1967). Yet another such autosomal recessive association (pseudoglioma with congenital osteoporosis) was recently reported by Saraux et al. (1967).

Thus, in conclusion, DSC is only one of a large number of genetically determined associations of skeletal and visual defects, many of which await better definition. Presumably, this variety of conditions in which single genes may affect the eye and the osseous system reflects some basic connexions between these organs during embryogenesis and postnatal development. The further study of such conditions may well afford insight into the nature of these connexions which are at present ill understood.

\section{Summary}

Several examples of unusual generalized skeletal dystrophies leading to dwarfism and in some cases identical to the condition known as dysplasia spondyloepiphysaria congenita were found in a series of 776 children with severe visual handicap in special schools in England and Wales. It is not possible to state categorically whether all these cases represent a single genetic entity with a wide range of phenotypic variation, or whether two or more distinct conditions are involved. This dystrophy (or dystrophies) is probably inherited in an autosomal dominant manner and is frequently, but not invariably, associated with high myopia, either congenital or of very early onset, which may lead to retinal detachments and blindness. Primary cataracts and buphthalmos may also occur as ocular complications of this syndrome which frequently includes perceptive deafness and, occasionally, cleft palate. The differential diagnosis of this syndrome or group of syndromes is considered within the context of a discussion concerning inherited associations between eye defects and generalized skeletal dystrophies.

We would like to thank Dr. F. A. Pearson and Mrs. Anne Green, who kindly provided the photographs and $x$-rays from which Fig. 1-3 were prepared. We are 
grateful to Dr. T. P. Mann and Dr. J. Rubin for information concerning the early medical history of Case 1, and to Dr. J. M. Cuthbert, Dr. D. A. N. Drury, and Dr. V. G. Peckar for arranging for $x$-ray examination of some of our patients. In addition, the medical records offices of several hospitals were most helpful in making notes and $x$-rays available regarding the condition of these children in early life before our survey.

We would like to thank the Principals and other staff of the schools which these children attend in facilitating our visits and placing their time freely at our disposal. We are greatly indebted to the Royal National Institute for the Blind for their financial support of the survey of children with severe visual handicaps, during which the subjects of the present report were studied. Lastly, we would like to thank the children themselves and their families for their unfailing courtesy and patience.

\section{REFERENCES}

Bach, D., Maroteaux, P., Schaeffer, P., Bitan, A., and Crumière, C. (1967). Dysplasie spondylo-épiphysaire congénitale avec anomalies multiples. Arch. franç. Pédiat., 24, 23.

Braun, O. H., and Meythaler, M. (1962). Dysostosis enchondralis (Typus Bartenwefer). Arch. Kinderheilk., 166, 89.

Cigala, F., and Golino, M. (1964). Considerazioni patogenetiche su un caso di morbo di Morquio-Ullrich. Pediatria (Napoli), $62,800$.

David, B. (1954). UUber einen dominanten Erbang bei einer polytopen enchondralen Dysostose Typ Pfaundler-Hurler. $Z$. Orthop., 84, 657.

Fairbank, T. (1947). Dysplasia epiphysialis multiplex. Brit. F. Surg., 34, 225.

Frandsen, E. (1966). Hereditary hyaloideo-retinal degeneration (Wagner) in a Danish family. Acta ophthal.(Kbh.), 44, 223.

Fraser, F. C., and Scriver, J. B. (1954). A hereditary factor in chondrodystrophia calcificans congenita. New Engl. f. Med., 250, 272.

Fraser, G. R., and Friedmann, A. I. (1967). The Causes of Blindness in Childhood. A study of 776 Children with Severe Visual Handicaps. John Hopkins Press, Baltimore.

Gasser, C. (1950). In Discussion to Alder, A. Konstitutionell bedingte Granulationsveränderungen der Leukocyten und Knochenveränderungen. Schweiz. med. Wschr., 80, 1097.

Hatt, J. J. (1952). Polydystrophie de Hürler chez un prématuré (association d'une cataracte congénitale). Strasbourg méd., 3, 893.

Kniest, W. (1952). Zur Abgrenzung des Dysostosis enchondralis von der Chondrodystrophie. Z.Kinderheilk., 70, 633

Lamy, M., and Maroteaux, P. (1960a). Le nanisme diastrophique. Presse méd., 68, 1977.
- and - (1960b). Les Chondrodystrophies Génotypiques. Expansion Scientifique Française, Paris.

Lenz, W. (1964). Anomalien des Wachstum und der Korperform. In Humangenetik, vol. II, pp. 86-89. Ed. by P. E. Becker. Thieme, Stuttgart.

McKusick, V. A. (1966). Heritable Disorders of Connective Tissue, 3rd ed., p. 467. Mosby, St. Louis.

Maroteaux, P., Lamy, M., and Bernard, J. (1957). La dysplasie spondylo-épiphysaire tardive. Presse méd., 65, 1205.

- Spranger, J., and Wiedemann, H. R. (1966). Der metatropische Zwergwuchs. Arch.Kinderheilk., 173, 211.

Mittwoch, U. (1963). The demonstration of mucopolysaccharide inclusions in the lymphocytes of patients with gargoylism. Acta haemat. (Basel), 29, 202.

Moore, W. T., and Federman, D. D. (1965). Familial dwarfism and 'stiff joints'. Arch. intern. Med., 115, 398.

Nordio, S., and Mantovani, V. (1956). Le sindromi di EhlersDanlos e di Brailsford-Morquio: loro rapporti nosologici. Minerva. Pediatrica, 8, 1316.

Penrose, L. S. (1961). Mutation. In Recent Advances in Human Genetics, p. 1. Ed. by L. S. Penrose. Churchill, London.

Roaf, R., Longmore, J. B., and Forrester, R. M. (1967). A childhood syndrome of bone dysplasia, retinal detachment and deafness. Develop. Med. Child. Neurol., 9, 464.

Rosenbloom, A. L., and Smith, D. W. (1965). The natural history of metaphyseal dysostosis. F. Pediat., 66, 857.

Saraux, H., Frézal, J., Roy, C., Aron, J. J., Hayat, B., and Lamy, M. (1967). Pseudo-gliome et fragilité osseuse héréditaire à transmission autosomale récessive. Ann. Oculist. (Paris), 200, 1241.

Scheie, H. G., Hambrick, G. W., Jr., and Barness, L. A. (1962;. A newly recognized forme fruste of Hurler's disease (gargoylism). Amer. F. Ophthal., 53, 753.

Silverman, F. N. (1961). Dysplasies épiphysaires: entité protéiforme. Ann. Radiol., 4, 883.

Spranger, J., and Wiedemann, H.-R. (1966a). Dysplasia spondyloepiphysaria congenita. Lancet, 2, 642.

-, and $-(1966 \mathrm{~b})$. Dysplasia spondyloepiphysaria congenita. Helv. paediat. Acta., 21, 598.

Stickler, G. B., Belau, P. G., Farrell, F. J., Jones, J. D., Pugh, D. G., Steinberg, A. G., and Ward, L. E. (1965). Hereditary progressive arthro-ophthalmopathy. Proc. Mayo Clin., 40, 433.

_- and Pugh, D. G. (1967). Hereditary progressive arthroophthalmopathy. II. Additional observations on vertebral abnormalities, a hearing defect, and a report of a similar case. ibid., 42, 495.

Uhlig, H. (1954). Dysostosis enchondralis-Typ Bartenwerfer. Arch. Kinderheilk, 148, 22.

von Noorden, G. K., Zellweger, H., and Pcnseti, I. V. (1960). Ocular findings in Morquio-Ullrich's disease: with report of two cases. Arch. Ophthal., 64, 585.

Correspondence to Dr. G. R. Fraser, Division of Medical Genetics, Dept. of Medicine, University of Washington, Seattle 98105, U.S.A. 